\title{
THE COMPARATIVE ANALYSIS OF INVESTOR SENTIMENT EFFECT ON TWO MAJOR EARTHQUAKES AND TSUNAMI INCIDENTS
}

\author{
DOI: 10.17261/Pressacademia.2019.1135 \\ PAP-IFC- V.10-2019(3)-p.12-16
}

\section{Oktay Tas ${ }^{1}$, Mine Ceren Sen ${ }^{2}$}

${ }^{1}$ Istanbul Technical University, Department of Management Engineering, Istanbul, Turkey tasokta@itu.edu.tr, ORCID: 0000-0002-8019-5308

${ }^{2}$ Istanbul Technical University, Department of Management, Istanbul, Turkey minecerensen@gmail.com, ORCID: 0000-0002-2199-0117

\section{To cite this document}

Tas, O., Sen, M.C. (2019). The comparative analysis of investor sentiment effect on two major earthquakes and tsunami incidents. PressAcademia Procedia (PAP), V.10, p.12-16.

Permanent link to this document: http://doi.org/10.17261/Pressacademia.2019.1135

Copyright: Published by PressAcademia and limited licensed re-use rights only.

\begin{abstract}
Purpose- Natural catastrophes such as earthquakes and tsunamis have been a great concern since the beginning of humanity and even before. Apart from the severe property damage they cause, these unforeseen incidents leave thousands of injured and dead. Events like the Indian Ocean and Japan earthquakes and tsunamis even lead to substantial impacts over the global economies. Through this interest, this study aims to determine the impacts of both incidents, over several stock market indices.

Methodology- In order to capture the influence of these events on various stock markets, an investor sentiment methodology is adopted. Trading volume is selected as an investor sentiment proxy and it is regressed against multiple macroeconomic data. The residuals of these analyses are assigned as investor sentiment indices for both cases respectively. Furthermore, an EGARCH model is developed to observe the impacts of investor sentiment associated with both incidents, on the considered stock markets.

Findings- The stock returns of Japan and Vietnam are negatively influenced by investor sentiment associated with the Indian Ocean Earthquake and Tsunami while the stock returns of Indonesia, South Korea, China and Singapore are positively influenced. Thus, the conditional volatilities of Sri Lanka, Indonesia, Thailand, Taiwan and Vietnam are negatively affected. Moreover, the stock returns of Indonesia, South Korea and Thailand are impacted negatively by investor sentiment related to the Japan Earthquake and Tsunami. Hence, the conditional volatility of Indonesia is positively influenced while it is negatively affected for Vietnam.

Conclusion- In contrast with the previous studies, there is strong evidence that most of the selected stock market indices are influenced by both events while the shocks brought by these events are long-lived through the selected stock markets. Moreover, Indian Ocean Earthquake and Tsunami incident seems to generate higher investor sentiment effects on the stock markets than Japan Earthquake and Tsunami incident does. Consequently, Indonesia and Vietnam are considered to be highly impacted by the investor sentiment related to both events. However, Hong Kong, Malaysia and India do not happen to have any investor sentiment effects regarding both earthquakes and tsunami incidents.
\end{abstract}

Keywords: Investor sentiment, 2004 Indian Ocean earthquake and tsunami, 2011 Japan earthquake and tsunami, EGARCH. JEL Codes: M10, M40, M41

\section{INTRODUCTION}

Since the beginning of humanity and even before, the world has witnessed quite a few natural catastrophes that result in loss of human life and damage in considerable property. Natural catastrophes such as earthquakes, hurricanes and tsunamis, which are unpredictable and uncontrollable, even lead to substantial impacts on the economy. Also, the influence of economic, environmental and social events on stock markets has been comprehensively discussed in the literature, while previous studies imply that incidents such as environmental accidents and energy crises exert a substantial effect on the behavior of the markets.

Regarding the facts mentioned hereinabove, this paper benefits from two major earthquakes and tsunami incidents, which are 2004, Indian Ocean Earthquake and Tsunami and 2011, Japan Earthquake and Tsunami, in order to investigate whether these incidents generate considerable impacts over the stock markets. In determining the effects of these events, an investor sentiment methodology is adopted.

The paper outline is as follows: Initially, the literature is examined in Section 2, where investor sentiment is discussed briefly, several proxies of investor sentiment are indicated and the literature on the incidents that are considered through this study are mentioned. In Section 3 , the equations of the analyses are constructed and data that are appointed in the research. In Section 4, the results of the analyses are implied respectively for both incidents. Finally, in Section 5 , the discussions considering the results are expressed and a brief conclusion of the paper is presented.

\section{LITERATURE REVIEW}




\subsection{Investor Sentiment}

The literature states that investor sentiment is associated with future stock returns. For instance, Baker and Wurgler (2006) determine that when the sentiment measures are low, subsequent returns are slightly high for small, young, unprofitable and non-dividend-paying stocks. However, when sentiment is high, these stocks have lower subsequent returns. In consistence, Bathia and Bredin (2013) observe that value stocks have low future returns when sentiment is high and they have high future returns when sentiment is low. Moreover, Hirshleifer (2001) determines that investor sentiment leads to overreaction and the overreaction causes excess volatility in returns. In consistence with the literature, Verma and Verma (2007) observe remarkable positive effects of investor sentiment on stock returns and substantial negative impacts of investor sentiment on volatilities, both for institutional and individual investors. Yu and Yuan (2011) also imply that the expected excess return and the conditional variance of the stock market are positively related in low sentiment periods. Thus, they indicate that there exists no relation in high sentiment periods.

Various studies have been conducted abundantly to measure investor sentiment and quantify its effects through the financial markets. Since there does not exist an investor sentiment proxy which is accurate and efficient, plenty of investor sentiment measures are existent. For instance, Baker and Wurgler (2007) use proxies like dividend premium, number of first-day returns on IPOs and equity share in new issues, to gauge investor sentiment. In order to remove the impacts of macroeconomic news, they apply a regression analysis where each proxy is regressed against macroeconomic data. Hereafter, Hudson and Green (2015) construct two new indices to analyze UK market-wide and institutional investor sentiment, using proxies which are the advances to declines ratio, the closed-end fund discount, the put-call open interest ratio and the Relative Strength Index.Hence, Baker and Stein (2004) only consider trading volume as a sentiment proxy in their study. Even though Lee et al. (1991) try to express the closed-end fund discount (CEFD) puzzle in terms of investor sentiment, Qui and Welch (2004) suggest that considering only the CEFD as a proxy may not be a significant indicator of investor sentiment. Furthermore, adopting a direct measure of investor sentiment, Fisher and Statman (2003) investigate the American Association of Individual Investors (AAII) survey and observe a significant positive relationship between changes in consumer confidence and changes in the sentiment. Through this study, trading volume is applied as a proxy in the measurement of investor sentiment since it seems to be the only coherent approach to generate a measure of investor sentiment which can be compared across various countries.

\subsection{Indian Ocean Earthquake and Tsunami}

The Indian Ocean Earthquake occurred on December 26, 2004, at $250 \mathrm{~km}$ offshore of the west coast of northern Sumatra, Indonesia. The earthquake which is indicated to have a magnitude over 9.0, also triggered a series of tsunami waves that spread across the Indian Ocean and caused damage to the shores of multiple countries which are near and far from the epicenter (Rossetto et al., 2007). With a death toll over thousands, the Boxing Day Tsunami incident is considered as one of the worst natural catastrophes recorded in human history.

The literature on stock market reaction to the Indian Ocean Earthquake and Tsunami incident is nonexistent while most studies concentrate on the geographical, environmental and socioeconomic impacts of the incident. For instance, Sheth et al. (2006) observe the damage caused by the tsunami event across India while Rigg et al. (2008) explore the impact of the incident through Thailand and the recovery process in the aftermath of the tsunami. Rossetto et al. (2007) indicate that the economy of Sri Lanka and Thailand, was not highly impacted by the catastrophe. However, they mention that the fishing and tourism industries in both countries were influenced badly by the incident. Horton et al. (2008) imply that fisherfolk and coastal businesses in Malaysia are also economically impacted by the event. According to Ramiah (2013), the equity markets are resilient to the Boxing Day Tsunami event. Though, there is an increase in the systematic risk for specific industries.

\subsection{Japan Earthquake and Tsunami}

The Great East Japan Earthquake struck on March 11, 2011, is the most powerful known earthquake to hit Japan (Hood et al., 2013). Also, it is considered as one of the five worldwide earthquakes to register a 9.0 or higher magnitude in the past one hundred years. The tsunami it triggered was its most damaging aspect leaving thousands of dead and damaging considerable property. The most notorious damage of the earthquake was that three nuclear reactors failed and exploded which caused the Fukushima nuclear incident. The Tohoku Earthquake was classified as a level-seven event on the International Nuclear Event Scale and said to pose a risk equal to the worst nuclear power plant accident in history, which was the Chernobyl disaster.

According to Ferreira and Karali (2015), the financial markets recover instantaneously after the shocks brought out by the earthquakes. They also prove that the volatility of the stock markets is not affected by the earthquakes, except for Japan. Consistently, Fakhry et al. (2018) find evidence that the influence of the Tohoku Earthquake on the financial markets is short lived. However, Valizadeh et al. (2017) suggest that stock markets of Japan and its trading partners, such as China, United States, Germany, France, Italy and Spain, were not easily and immediately recovered after the earthquake. Hood et al. (2013) study the investor reaction in Japan to the 2011 Tohoku Earthquake and concentrate on individual and foreign investor behavior. They imply that a significant loss in the stock market took place instantly after the earthquake. In consistence, Luo (2012) finds a negative shock brought by the earthquake in six major stock markets.

\section{DATA AND METHODOLOGY}

The EGARCH model is adopted in this study since the model helps to capture the asymmetric effects significantly while overcoming the nonnegativity constraints. The conditional mean and conditional variance equations are presented respectively.Sent $t_{t}$ in the mean equation appoints the investor sentiment and determines the macroeconomic shocks, whereas the coefficient $\theta_{1}$ evaluates the investor sentiment effects on the returns. The coefficient $\gamma_{2}$ in the variance equation determines the impact of negative shocks on returns as well as the leverage effect. The coefficient $\gamma_{3}$ is known as the persistence parameter. Consequently, the coefficient $\gamma_{4}$ indicates the influence of investor sentiment on the conditional variance of returns. The EGARCH model which is adopted through this study, is considered in both cases.

$$
\mu_{t}=\theta_{0}+\theta_{1} \text { Sent }_{t}+\varepsilon_{t}
$$




$$
\log \left(h_{t}\right)=\gamma_{0}+\gamma_{1} \frac{\left|\varepsilon_{t-1}\right|}{\sqrt{h_{t-1}}}+\gamma_{2} \frac{\varepsilon_{t-1}}{\sqrt{h_{t-1}}}+\gamma_{3} \log \log \left(h_{t-1}\right)+\gamma_{4} \operatorname{Sent}_{t-1}
$$

Initially, daily trading volume data of stock market indices of Indonesia and Japan are applied as investor sentiment proxies respectively. Hence, the data are not directly used as investor sentiment proxies through the study since the changes in trading volume data may also be the indicators of many macroeconomic events. Therefore, a regression analysis is carried out for both cases, where daily trading volume data of the countries are the dependent variables and several macroeconomic data such as Consumer Price Index (CPI), Producer Price Index (PPI), Unemployment Rate, Money Supply (M2) and Industrial Production are the independent variables. Also, the consumer confidence indices of Indonesia and Japan are appointed as dummy variables through the analyses. The general model which is constructed to create an investor sentiment index is as follows:

$$
T R A D E_{-} V O L U M E_{t}=\theta_{0}++\theta_{1} C P I_{t}+\theta_{2} P P I_{t}+\theta_{3} U N E M P_{t}+\theta_{4} M 2_{t}+\theta_{5} I N D_{-} P R O D_{t}+\theta_{6} D U M M Y_{-} C C I_{t}
$$

Since the macroeconomic data are mostly released on a monthly basis, they must be converted into a daily frequency. Therefore, the cubic spline interpolation method is adopted to transform these control variables into a daily frequency. The trading volume and the macroeconomic data are retrieved from Thomson Reuters.

For the second part of the analyses, daily stock market index returns of several countries such as China (SSEC), Hong Kong (HSI), India (SENSEX), Indonesia (JKSE), Japan (Nikkei 225), Malaysia (KLSE), Singapore (STI), South Korea (KOSPI), Sri Lanka (CSE), Taiwan (TWII), Thailand (SETI) and Vietnam (VNI) are used as dependent variables in the EGARCH models to observe the impacts of investor sentiment associated with the incidents which are selected through the study. The selected countries consist of the major and minor trading partners of both Indonesia and Japan which are also considered to be geographically close to these countries.

\section{FINDINGS}

\subsection{Investor Sentiment Effect Related to 2004, Indian Ocean Earthquake and Tsunami}

For the first step of the study, a regression analysis is applied where daily trading volume data of JKSE, for the period between August 2004 and May 2005, is the dependent variable and various macroeconomic data are the independent variables. The residuals of this regression are appointed as the investor sentiment index in the following analyses that capture the investor sentiment effects. To examine the influence of investor sentiment related to 2004, Indian Ocean Earthquake and Tsunami, daily stock market index returns of the selected countries, for the period between August 2004 and May 2005, are used as dependent variables in the EGARCH models. The outcomes of the EGARCH models are shown in Table 1 . The initial numbers that are attained, are the coefficients and the numbers in the brackets express the probabilities of the coefficients in the analyses.

\begin{tabular}{|c|c|c|c|c|c|c|c|c|c|c|c|c|}
\hline & CSE & HSI & JKSE & KLSE & KOSPI & NIK & SENSEX & SETI & SSEC & STI & TWII & VNI \\
\hline \multirow[b]{2}{*}{$\theta_{0}$} & 0,0020 & 0,0006 & 0,0019 & 0,0005 & 0,0007 & 0,0004 & 0,0015 & 0,0006 & $-0,0020$ & 0,0005 & 0,0003 & $3,7 \mathrm{E}-05$ \\
\hline & $(0,0001$ & $(0,2703$ & $(0,0063$ & $(0,2094$ & $(0,3683$ & $(0,4430$ & $(0,0420$ & $(0,3928$ & $(0,0150$ & $(0,2490$ & $(0,6628$ & $(0,9037$ \\
\hline \multirow[b]{2}{*}{$\theta_{1}$} & 0,0004 & $-0,0006$ & 0,0043 & 0,0007 & 0,0037 & $-0,0021$ & $-0,0024$ & 0,0018 & 0,0051 & 0,0024 & 0,0005 & $-0,0026$ \\
\hline & $(0,8197$ & $(0,6355$ & $(0,0000$ & $(0,3417$ & $(0,0938$ & $(0,0458$ & $(0,1235$ & $(0,3674$ & $(0,0182$ & $(0,0062$ & $(0,7652$ & $(0,0000$ \\
\hline \multirow[b]{2}{*}{$\gamma_{0}$} & $-1,1859$ & $-4,5846$ & $-2,4845$ & $-15,983$ & $-1,9812$ & $-16,111$ & $-1,0631$ & $-13,697$ & $-2,5020$ & $-2,9878$ & $-3,5930$ & $-4,9596$ \\
\hline & $(0,0489$ & $(0,0731$ & $(0,0345$ & $(0,0022$ & $(0,0145$ & $(0,0000$ & $(0,1100$ & $(0,0000$ & $(0,0013$ & $(0,1842$ & $(0,0000$ & $(0,0000$ \\
\hline \multirow[b]{2}{*}{$\gamma_{1}$} & 0,1107 & $-0,0477$ & 0,0942 & $-0,2381$ & $-0,2057$ & 0,4849 & $-0,0203$ & $-0,1112$ & 0,6929 & $-0,0021$ & $-0,2429$ & 0,3334 \\
\hline & $(0,0854$ & $(0,7091$ & $(0,4744$ & $(0,2423$ & $(0,0284$ & $(0,0000$ & $(0,8372$ & $(0,5193$ & $(0,0000$ & $(0,9895$ & $(0,0567$ & $(0,0457$ \\
\hline \multirow[b]{2}{*}{$\gamma_{2}$} & $-0,0510$ & $-0,1599$ & $-0,2322$ & 0,0260 & $-0,2380$ & $-0,0214$ & $-0,1257$ & 0,1335 & $-0,3572$ & $-0,2128$ & $-0,2411$ & 0,4140 \\
\hline & $(0,2224$ & $(0,0519$ & $(0,0010$ & $(0,8358$ & $(0,0110$ & $(0,7650$ & $(0,0512$ & $(0,2508$ & $(0,0001$ & $(0,0314$ & $(0,0055$ & $(0,0005$ \\
\hline \multirow{3}{*}{$\gamma_{3}$} & 0,8910 & 0,5355 & 0,7428 & $-0,5345$ & 0,7637 & $-0,6240$ & 0,8854 & $-0,4910$ & 0,7724 & 0,7088 & 0,6066 & 0,5708 \\
\hline & $(0,0000$ & $(0,0384$ & $(0,0000$ & $(0,2796$ & $(0,0000$ & $(0,0000$ & $(0,0000$ & $(0,1025$ & $(0,0000$ & $(0,0010$ & $(0,0000$ & $(0,0000$ \\
\hline & $-0,4205$ & $-0,4207$ & $-0,3950$ & $-0,1403$ & $-0,0424$ & $-0,1598$ & 0,0704 & $-0,5071$ & $-0,2232$ & $-0,2637$ & $-0,3994$ & $-0,4883$ \\
\hline$\gamma_{4}$ & $(0,0158$ & $(0,1183$ & $(0,0583$ & $(0,6138$ & $(0,8116$ & $(0,3091$ & $(0,6731$ & $(0,0803$ & $(0,3392$ & $(0,3382$ & $(0,0270$ & $(0,0268$ \\
\hline
\end{tabular}

Table 1: EGARCH Results Associated with the Indian Ocean Earthquake and Tsunami Event

Coefficient $\theta_{1}$ is monitored to see the effects of investor sentiment on returns. $\theta_{1}$ seems to be significant and negative for NIK and VNI, which represents that the returns of these stock market indices are negatively affected by the investor sentiment related to the 2004 Indian Ocean Earthquake and Tsunami incident. However, the stock market returns of JKSE, KOSPI, SSEC and STI are positively influenced by investor sentiment since $\theta_{1}$ is significant and positive for these stock market indices. Coefficient $\gamma_{2}$ is controlled to determine the asymmetric volatility in the model. $\gamma_{2}$ is significant and negative for all stock market indices, except for CSE, KLSE, NIK and SETI, which remarks that the negative shocks exert a higher impact on each $h_{t}$ than the positive shocks do. Coefficient $\gamma_{3}$ measures the persistence in conditional volatility. If $\gamma_{3}$ is large, volatility is said to take a long time to fade away following 2004, Indian Ocean Earthquake and Tsunami incident in the market. Since $\gamma_{3}$ is significant, positive and high for the stock market indices such as CSE, HSI, JKSE, KOSPI, SENSEX, SSEC, STI, TWII and VNI, they seem to show high persistence. Besides, coefficient $\gamma_{4}$ is evaluated to explore the investor sentiment effects on the conditional volatility. Though, $\gamma_{4}$ is statistically significant for CSE, JKSE, SETI, TWII and VNI stock markets. However, the coefficient is negative for all these stock market indices. Therefore, it is observed that the conditional volatilities of these stock markets are impacted negatively by the investor sentiment associated with the Indian Ocean Earthquake and Tsunami event. 


\subsection{Investor Sentiment Effect Related to 2011, Japan Earthquake and Tsunami}

In the initial part of the study, a regression analysis is carried out where daily trading volume data of Nikkei 225 , for the period between January 2011 and October 2011, is the dependent variable and a group of macroeconomic data are the independent variables. The residuals of this regression are assigned as the investor sentiment index in the following analyses, that capture the impacts of investor sentiment. To determine the effects of investor sentiment associated with 2011, Japan Earthquake and Tsunami, daily stock market index returns of the selected countries, for the period between January 2011 and October 2011, are appointed as dependent variables in the EGARCH models. The outcomes of the EGARCH models are presented in Table 2.

Table 2: EGARCH Results Related to the Japan Earthquake and Tsunami Incident

\begin{tabular}{|c|c|c|c|c|c|c|c|c|c|c|c|c|}
\hline & CSE & HSI & JKSE & KLSE & KOSPI & NIK & SENSEX & SETI & SSEC & STI & TWII & VNI \\
\hline \multirow{2}{*}{$\theta_{0}$} & $-0,0006$ & $-0,0025$ & 9,7E-05 & $-0,0004$ & $-0,0005$ & $-0,0009$ & $-0,0012$ & $7,8 \mathrm{E}-05$ & $-0,0015$ & $-0,0008$ & $-0,0014$ & $-0,0015$ \\
\hline & $(0,3265$ & $(0,0000$ & $(0,9227$ & $(0,4081$ & $(0,5453$ & $(0,2677$ & $(0,1449$ & $(0,9238$ & $(0,0034$ & $(0,2479$ & $(0,0000$ & $(0,0687$ \\
\hline \multirow{2}{*}{$\theta_{1}$} & $-0,0050$ & $-0,0037$ & $-0,0151$ & $-0,0007$ & $-0,0143$ & 0,0003 & $-0,0061$ & $-0,0113$ & 0,0023 & $-0,0041$ & $-0,0040$ & 0,0038 \\
\hline & $(0,1903$ & $(0,5181$ & $(0,0417$ & $(0,7844$ & $(0,0357$ & $(0,9643$ & $(0,3100$ & $(0,0377$ & $(0,5484$ & $(0,4031$ & $(0,4429$ & $(0,4445$ \\
\hline \multirow[b]{2}{*}{$\gamma_{0}$} & $-4,1590$ & $-0,0981$ & $-7,8889$ & $-0,2294$ & $-0,4780$ & $-1,7112$ & $-0,2518$ & $-0,7165$ & $-1,0309$ & $-0,6089$ & $-0,4238$ & $-2,0136$ \\
\hline & $(0,0045$ & $(0,5113$ & $(0,0000$ & $(0,0163$ & $(0,0182$ & $(0,0025$ & $(0,1006$ & $(0,0116$ & $(0,0000$ & $(0,0119$ & $(0,0000$ & $(0,0213$ \\
\hline \multirow[b]{2}{*}{$\gamma_{1}$} & 0,5464 & $-0,0578$ & 0,5528 & 0,0131 & 0,1186 & 0,1975 & 0,0362 & 0,1436 & $-0,4048$ & 0,1231 & $-0,0939$ & 0,4682 \\
\hline & $(0,0004$ & $(0,3070$ & $(0,0001$ & $(0,7384$ & $(0,3288$ & $(0,2531$ & $(0,4794$ & $(0,2324$ & $(0,0000$ & $(0,2250$ & $(0,0140$ & $(0,0112$ \\
\hline \multirow[b]{2}{*}{$\gamma_{2}$} & 0,1013 & $-0,1814$ & $-0,3284$ & $-0,1365$ & $-0,1830$ & $-0,3573$ & $-0,1503$ & $-0,2217$ & $-0,1372$ & $-0,1578$ & $-0,3051$ & $-0,0915$ \\
\hline & $(0,3044$ & $(0,0000$ & $(0,0008$ & $(0,0000$ & $(0,0046$ & $(0,0003$ & $(0,0006$ & $(0,0004$ & $(0,0004$ & $(0,0176$ & $(0,0000$ & $(0,3066$ \\
\hline \multirow[b]{2}{*}{$\gamma_{3}$} & 0,6120 & 0,9816 & 0,1252 & 0,9784 & 0,9551 & 0,8248 & 0,9739 & 0,9333 & 0,8537 & 0,9442 & 0,9440 & 0,8151 \\
\hline & $(0,0000$ & $(0,0000$ & $(0,2595$ & $(0,0000$ & $(0,0000$ & $(0,0000$ & $(0,0000$ & $(0,0000$ & $(0,0000$ & $(0,0000$ & $(0,0000$ & $(0,0000$ \\
\hline \multirow[b]{2}{*}{$\gamma_{4}$} & $-0,7882$ & $-0,0503$ & 2,4897 & $-0,1328$ & $-0,5198$ & $-0,7910$ & $-0,0601$ & $-0,3181$ & 0,2201 & 0,3277 & $-0,3640$ & $-1,6390$ \\
\hline & $(0,1199$ & $(0,9216$ & $(0,0030$ & $(0,7434$ & $(0,4047$ & $(0,2098$ & $(0,9118$ & $(0,6153$ & $(0,5252$ & $(0,6287$ & $(0,3663$ & $(0,0103$ \\
\hline
\end{tabular}

$\theta_{1}$ is significant and negative for JKSE, KOSPI and SETI, which represents that the returns of these stock market indices are negatively affected by the investor sentiment associated with the Japan Earthquake and Tsunami incident. Coefficient $\gamma_{2}$, which is explored to ascertain the asymmetric volatility in the model, is significant and negative for all the stock market indices, except for CSE and VNI. This demonstrates that the negative shocks generate a greater influence on each $h_{t}$ than the positive shocks do. Since $\gamma_{3}$ is significant, positive and high for all the stock market indices, except for JKSE, they exert a high persistence and the volatility takes a long time to vanish following 2011 , Japan Earthquake and Tsunami event in the market. Likewise, coefficient $\gamma_{4}$ is checked to examine the impacts of investor sentiment on conditional volatility. Herewith, $\gamma_{4}$ is statistically significant only for the stock market indices such as JKSE and VNI.

\section{CONCLUSION}

This study aims to determine the impacts of 2004, Indian Ocean Earthquake and Tsunami and 2011, Japan Earthquake and Tsunami incidents, over several stock market indices in terms of investor sentiment. Through this study, it is observed that there exist substantial investor sentiment effects on a considerable number of stock markets.For instance, the stock returns of Japan and Vietnam are negatively influenced by investor sentiment related to the 2004 Indian Ocean Earthquake and Tsunami event while the stock returns of Indonesia, South Korea, China and Singapore are positively influenced. Thus, in contrast with the studies of Rossetto et al. (2007) and Ramiah (2013), it is determined that the conditional volatility of stock returns of Sri Lanka, Indonesia, Thailand, Taiwan and Vietnam are negatively affected by the investor sentiment associated with the catastrophe.

Furthermore, the stock returns of Indonesia, South Korea and Thailand are negatively impacted by the investor sentiment related to the 2011 Japan Earthquake and Tsunami incident. Hence, the conditional volatility of stock market returns of Indonesia is positively influenced while they are negatively affected for the stock market of Vietnam. Despite the previous studies conducted by Ferreira and Karali (2015) and Fakhry et al. (2018), which suggest that financial markets are resilient to earthquake shocks, the shocks that are constituted by 2011 , Japan Earthquake are examined to be long-lived for all the considered stock market indices, except for the Indonesian stock market.

Consequently, it is determined that the Indian Ocean Earthquake and Tsunami event generates higher investor sentiment impacts among the selected stock markets than the Japan Earthquake and Tsunami event does. Considering the epicenter of Indian Earthquake and Tsunami incident, this results seems to be consistent since the location where the Indian Ocean Earthquake and Tsunami event took place is geographically more inclined to have impacts over the neighbor countries.

Moreover, Indonesia seems to be highly impacted by the investor sentiment associated with both incidents since both the returns and conditional volatility of stock returns for the Indonesian stock market (JKSE) are affected in both of these events. The Vietnamese stock market (VNI) follows JKSE by being the second most influenced stock market.Even though Hong Kong and Malaysia are the major trading partners of both Indonesia and Japan, they do not happen to have any investor sentiment effects associated with both incidents. Also, in India, which is a major trading partner of Japan and a minor trading partner of Indonesia, there does not exist any influence of investor sentiment related to both events.

\section{REFERENCES}

Baker, M., \& Stein, J. C. (2004). Market liquidity as a sentiment indicator. Journal of Financial Markets, 7, 271 - 299. 
Baker, M., \&Wurgler, J. (2006). Investor sentiment and the cross-section of stock returns. The Journal of Finance, 61 (4), 1645 - 1680.

Baker, M., \&Wurgler, J. (2007). Investor sentiment in the stock market. Journal of Economic Perspectives, 21 (2), 129 - 151.

Bathia, D., \& Bredin, D. (2013). An examination of investor sentiment effect on G7 stock market returns. The European Journal of Finance, 19 (9), 909 - 937

Fakhry, B., Aktan, B., Masood, O., Tvaronavičienè, M., \&Celik, S. (2018). The impact of a recent natural disaster on the Japanese financial markets: Empirical evidence. Journal of Competitiveness, 10 (2), 56 - 71.

Ferreira, S., \&Karali, B. (2015). Do earthquakes shake stock markets? PLos ONE, 10 (7).

Fisher, K. L., \& Statman, M. (2003). Consumer confidence and stock returns. The Journal of Portfolio Management, 30 (1), 115 - 127.

Hirshleifer, D. (2001). Investor psychology and asset pricing. The Journal of Finance, 56 (4), 1533 - 1597.

Hood, M., Kamesaka, A., Nofsinger, J., \& Tamura, T. (2013). Investor response to a natural disaster: Evidence from Japan's 2011 earthquake. Pacific-Basin Finance Journal, 25, 240 - 252.

Horton, B., Bird, M., Birkland, T., Cowie, S., Eong, O. J., Hawkes, A., . . Yasin, Z. (2008). Environmental and socioeconomic dynamics of the Indian Ocean tsunami in Penang, Malaysia. Singapore Journal of Tropical Geography, 29, 307 - 324.

Hudson, Y., \& Green, C. J. (2015). Is investor sentiment contagious? International sentiment and UK equity returns. Journal of Behavioral and Experimental Finance, 5, 46 - 59.

Lee, C. M., Shleifer, A., \& Thaler, R. H. (1991). Investor sentiment and the closed-end fund puzzle. The Journal of Finance, 46 (1), 75 - 109. Luo, N. (2012). The impact of natural disasters on global stock market: The case of the Japanese 2011 earthquake.

Qui, L., \& Welch, I. (2004). Investor sentiment measures. NBER Working Paper.

Ramiah, V. (2013). Effects of the Boxing Day tsunami on the world capital markets. Review of Quantitative Finance and Accounting, 40 (2), $383-401$.

Rigg, J., Grundy-Warr, C., Law, L., \& May, T.-M. (2008). Grounding a natural disaster: Thailand and the 2004 tsunami. Asia Pacific Viewpoint, $49(2), 137-154$

Rossetto, T., Peiris, N., Pomonis, A., Wilkinson, S. M., Del Re, D., Koo, R., \&Gallocher, S. (2007). The Indian Ocean tsunami of December 24, 2004: Observations in Sri Lanka and Thailand. Nat Hazards, 42, 105 - 124.

Sheth, A., Sanyal, S., Jaiswal, A., \& Gandhi, P. (2006). Effects of the December 2004 Indian Ocean tsunami on the Indian mainland. Earthquake Spectra, 22 (3), 435 - 473.

Valizadeh, P., Karali, B., \& Ferreira, S. (2017). Ripple effects of the 2011 Japan earthquake on international stock markets. Research in International Business and Finance, 41, 556 - 576.

Verma, R., \&Verma, P. (2007). Noise trading and stock market volatility. Journal of Multinational Financial Management, 17, 231- 243.

Yu, J., \& Yuan, Y. (2011). Investor sentiment and the mean-variance relation. Journal of Financial Economics, 100,367 - 381. 